\title{
Metal-Catalyst-Free Synthesis and Characterization of Single-Crystalline Silicon Oxynitride Nanowires
}

\author{
Shuang Xi, ${ }^{1}$ Tielin Shi, ${ }^{1}$ Liangliang Xu, ${ }^{2}$ Zirong Tang, ${ }^{2}$ \\ Dan Liu, ${ }^{1}$ Xiaoping Li, ${ }^{2}$ and Shiyuan Liu ${ }^{1}$ \\ ${ }^{1}$ State Key Laboratory of Digital Manufacturing Equipment and Technology, Huazhong University of Science and Technology, \\ Wuhan 430074, China \\ ${ }^{2}$ Wuhan National Laboratory for Optoelectronics, Huazhong University of Science and Technology, Wuhan 430074, China
}

Correspondence should be addressed to Zirong Tang, zirong@mail.hust.edu.cn

Received 13 January 2012; Revised 1 April 2012; Accepted 3 April 2012

Academic Editor: Vo-Van Truong

Copyright (C) 2012 Shuang Xi et al. This is an open access article distributed under the Creative Commons Attribution License, which permits unrestricted use, distribution, and reproduction in any medium, provided the original work is properly cited.

\begin{abstract}
Large quantities of single-crystal silicon oxynitride nanowires with high $\mathrm{N}$ concentration have been synthesized directly on silicon substrate at $1200^{\circ} \mathrm{C}$ without using any metal catalyst. The diameter of these ternary nanowires is ranging from 10 to $180 \mathrm{~nm}$ with log-normal distribution, and the length of these nanowires varies from a few hundreds of micrometers to several millimeters. A vapor-solid mechanism was proposed to explain the growth of the nanowires. These nanowires are grown to form a disordered mat with an ultrabright white nonspecular appearance. The mat demonstrates highly diffusive reflectivity with the optical reflectivity of around $80 \%$ over the whole visible wavelength, which is comparable to the most brilliant white beetle scales found in nature. The whiteness might be resulted from the strong multiscattering of a large fraction of incident light on the disordered nanowire mat. These ultra-bright white nanowires could form as reflecting surface to meet the stringent requirements of bright-white lightemitting-diode lighting for higher optical efficiency. They can also find applications in diverse fields such as sensors, cosmetics, paints, and tooth whitening.
\end{abstract}

\section{Introduction}

In recent years, silicon oxynitride $\left(\mathrm{SiO}_{x} \mathrm{~N}_{y}\right)$ has received considerable attention as an important dielectric material, due to its superior electrical and physical properties [1]. The fully compatibility of this material with conventional $\mathrm{Si}$ processing technology greatly accelerates its application in electronic and optoelectronic devices [2]. $\mathrm{SiO}_{x} \mathrm{~N}_{y}$ has a static dielectric constant that increases linearly with the nitrogen concentration from $\mathrm{SiO}_{2}(\varepsilon=3.8)$ to $\mathrm{Si}_{3} \mathrm{~N}_{4}(\varepsilon=7.8)$ [3], and a large refractive index ranging from 1.45 up to $2.0[4,5]$. A high concentration of nitrogen in $\mathrm{SiO}_{x} \mathrm{~N}_{y}$ is generally desired: by increasing N/O ratio, a higher dielectric constant and refractive index can be obtained $[6,7]$. However, most of the silicon oxynitride materials studied up to now have a nitrogen concentration less than 15 at. $\%[8,9]$, and primarily are amorphous $\mathrm{SiO}_{x} \mathrm{~N}_{y}$ films. As a result, the properties of silicon oxynitride materials with high $\mathrm{N}$ concentration remain largely unexplored [10].
On the other hand, one-dimensional nanostructures have attracted steadily growing interests due to their peculiar properties and applications superior to their bulk counterparts $[11,12]$. For example, it has been demonstrated that nanowires actually can be grown to form one of the most strongly scattering materials in a recent study [13]. Light scattering in nanowire materials has also been shown significant importance to optimize the external efficiency of nanowire-based photovoltaic devices [14, 15]. Furthermore, multielement alloy nanowires possess the characteristics of variety by adjusting their chemical composition and physical structure. Therefore, it is important to synthesize 1D $\mathrm{SiO}_{x} \mathrm{~N}_{y}$ nanostructures and explore their properties. However, ternary $\mathrm{SiO}_{x} \mathrm{~N}_{y}$ nanowires, especially $\mathrm{N}$-rich singlecrystal $\mathrm{SiO}_{x} \mathrm{~N}_{y}$ nanowires, have been seldom reported. Recently, Gu et al. [16] reported the successful fabrication of N-rich single crystalline $\mathrm{SiO}_{x} \mathrm{~N}_{y}$ nanowires using both $\mathrm{Fe}\left(\mathrm{NO}_{3}\right)_{3} 9 \mathrm{H}_{2} \mathrm{O}$ and $\mathrm{Co}\left(\mathrm{NO}_{3}\right)_{2} 4 \mathrm{H}_{2} \mathrm{O}$ as catalyst precursors, while little information is available regarding their optical 
properties. It is desirable that nanowries could be synthesized without metal catalyst since catalyst contaminations might affect the characteristics of the nanowire, especially their optical properties.

In this work, we report the catalyst-free synthesis of bulk single-crystal $\mathrm{SiO}_{x} \mathrm{~N}_{y}$ nanowires with high $\mathrm{N}$ concentration. The chemical composition and structural characterization of these nanowires have been investigated, and the growth mechanism is discussed. The optical properties of the disordered $\mathrm{SiO}_{x} \mathrm{~N}_{y}$ nanowire mat have also been studied.

\section{Experimental Details}

In a typical synthesis procedure, the single-crystalline $\mathrm{Si}$ wafer [100] with a native oxidation layer (5 nm) was first dipped into acetone under ultrasonic agitation for $10 \mathrm{~min}$ to erase the surface contaminations. Then, the Si wafer was loaded to a quartz crucible boat and placed in the central region of an alumina tube furnace (GSL-1400X). Before the experiment, the furnace was evacuated to $10^{-3}$ Torr and then flushed with $\mathrm{N}_{2}(99.999 \%)$ to eliminate the oxygen and moisture in the chamber. The crucible boat was heated to $1200^{\circ} \mathrm{C}$ at the heating rate of $15^{\circ} \mathrm{C} / \mathrm{min}$ under a $\mathrm{N}_{2}$ flow of 50 standard cubic centimeters per minute $(\mathrm{sccm})$. When the temperature reached the preset value, the gas flux was switched to mixture gas flow of $\mathrm{H}_{2}(5 \%) / \mathrm{N}_{2}(99.999 \%)$ at a rate of $100 \mathrm{sccm}$. The growth time can be varied to obtain nanowire mats with different thickness. During the cooling process, only $\mathrm{N}_{2}(99.999 \%)$ was used as the feed gas. When the furnace was naturally cooled down to room temperature, ultrabright white products were observed on the wafer.

The structure, morphologies, and composition of the products were characterized with scanning electron microscope (SEM, JEOL JSM-5510LV), high-resolution transmission electron microscope (HRTEM, FEI-F20 with EDS attachment and JEOL 2010), and selected-area electron diffraction (SAED). X-ray photoelectron spectroscopy (XPS, Kratos Axis Ultra DLD) and Fourier transform-infrared Spectroscope (FT-IR, VERTEX 70) were also used to investigate their chemical composition. The optical reflectivity was measured under the wavelength from 400 to $780 \mathrm{~nm}$ using UV-Vis spectrophotometer (Lambda 35) with a $50 \mathrm{~mm}$ integrating sphere. Photoluminescence (PL) property was also studied using PL instrument (FP-6500) at room temperature with a xenon lamp line of $258 \mathrm{~nm}$ as the excitation source.

\section{Result and Discussion}

3.1. Morphologies and Structures. The SEM image see Figure 1(a) shows that the synthesized nanowires are up to several millimeters in length, with high density, and random directions to form a disordered thick mat. For each individual nanowire, the diameter is uniform along its entire length, and the surface of these nanowires is smooth and clear without any residues. To pursue detailed structural information on a single nanowire, TEM investigations were applied. Figure 1(b) shows a TEM image of $\mathrm{SiO}_{x} \mathrm{~N}_{y}$ nanowires, where different diameters are observed. Y-shaped nanowires are also observed as marked in the figure. A histogram of the diameter distribution of 285 nanowires from TEM measurements is shown in Figure 1(c). It is shown that the diameter distribution follows a log-normal distribution function (solid line in the figure) with the peak distribution of around $42 \mathrm{~nm}$.

A higher magnification TEM image of the Y-shaped $\mathrm{SiO}_{x} \mathrm{~N}_{y}$ nanowire is shown in Figure 2(a), which is obtained from one of the junctions between the stem and extended branch marked in Figure 1(b). From the picture, it appears that the diameter near the root of the Y-branch is almost the same with that of the stem, while close to the tip, its diameter gets smaller. To better understand the formation of the branch, a HRTEM image of the junction is obtained as shown in Figure 2(b). It is found that the $\mathrm{SiO}_{x} \mathrm{~N}_{y}$ nanowire consists of a single crystalline phase throughout the whole structure with a clean backbone-to-branch junction, indicating the possibly epitaxial growth of the branch from the stem. EDS analyses reveal that the chemical composition of the nanowire consists of three elements including $\mathrm{Si}, \mathrm{N}$, and $\mathrm{O}$. Detailed composition result shows that the nanowire has the high concentration of $\mathrm{N}$ of around 54.27 at. $\%$ and the $\mathrm{O}$ concentration around 7.44 at. $\%$. These $\mathrm{N}$-rich nanowires may inherit the high refractive index of their bulk materials, which renders strong photonic property [15]. Figures 2(c) and 2(d) are the typical HRTEM images of the prepared nanowires, and the insets correspond to SAED patterns of the nanowires. HRTEM images show that the $\mathrm{SiO}_{x} \mathrm{~N}_{y}$ nanowires grew along two different directions with zone axes of [2 $\overline{2} 1]$ (Figure 2(c)) and [11ㅣ] (Figure 2(d)), respectively, and the lattice spacings of the single crystal nanowire were measured to be 0.679 and $0.415 \mathrm{~nm}$, respectively.

XPS has been employed to analyze the chemical bonding within the nanowires and to give insight into their composition, where monochromatic $\mathrm{Al} \mathrm{K} \alpha \mathrm{X}$-ray source was operated at $150 \mathrm{~W}$. Figure 3 (a) shows the XPS spectra of the obtained nanowires with $\mathrm{Si} 2 \mathrm{p}, \mathrm{N}$ 1s, and $\mathrm{O}$ 1s signals. Three strong XPS signals display direct evidence of the existence of $\mathrm{Si}, \mathrm{N}$, and $\mathrm{O}$ elements. The peak of $\mathrm{N} 1 \mathrm{~s}$, located at $397.5 \mathrm{eV}$, shifts to a higher binding energy compared with the $397.0 \mathrm{eV}$ peak which is attributed to $\mathrm{N}$ combined with three $\mathrm{Si}$ atoms [17], due to the formation of $\mathrm{N}-\mathrm{O}$ bond [18]. Deconvolution of the $2 \mathrm{p}$ Si spectrum yields three GaussianLorentzian components centered at 101, 102, and $103.2 \mathrm{eV}$ which are assigned to, respectively, $\mathrm{Si}-\mathrm{N}$ and $\mathrm{Si}-\mathrm{O}-\mathrm{N}$ and $\mathrm{Si}-$ O bond configurations [19].

The chemical composition of these nanowires is further confirmed by FT-IR spectrometer. The broad FT-IR spectrum from 400 to $4000 \mathrm{~cm}^{-1}$ is shown in Figure $3(\mathrm{~b})$. The absorption band at 492 originates from the vibrations of the $\mathrm{Si}-\mathrm{O}-\mathrm{Si}$ bonds. Peaks corresponding to the vibration modes of Si-N bonds appear at 846, 887, and $924 \mathrm{~cm}^{-1}$ [20]. The band of $1048 \mathrm{~cm}^{-1}$ indicates the asymmetrical stretching vibration of $\mathrm{Si}-\mathrm{O}$ bonds. The $3440 \mathrm{~cm}^{-1}$ and $1632 \mathrm{~cm}^{-1}$ adsorption bands are attributed respectively to the stretching and bending vibrations of $\mathrm{O}-\mathrm{H}$ bond for adsorbed water, which may come from its adsorption on the $\mathrm{SiO}_{x} \mathrm{~N}_{y}$ nanowire surface [21]. 


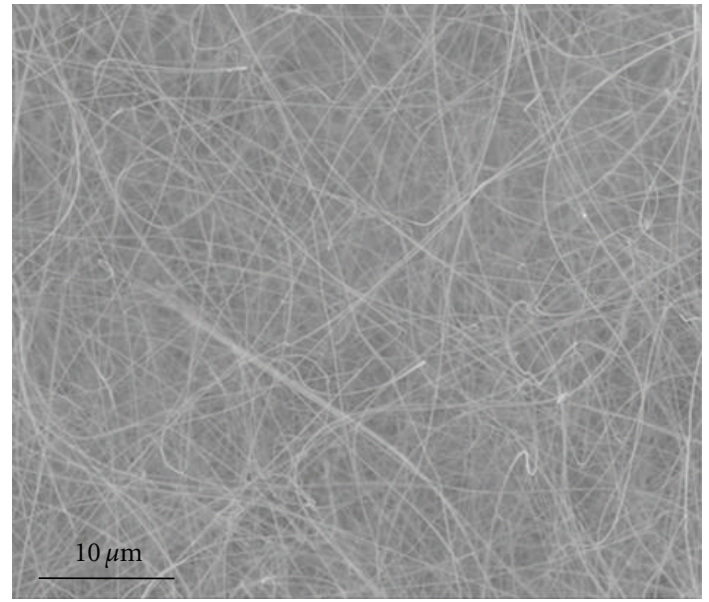

(a)

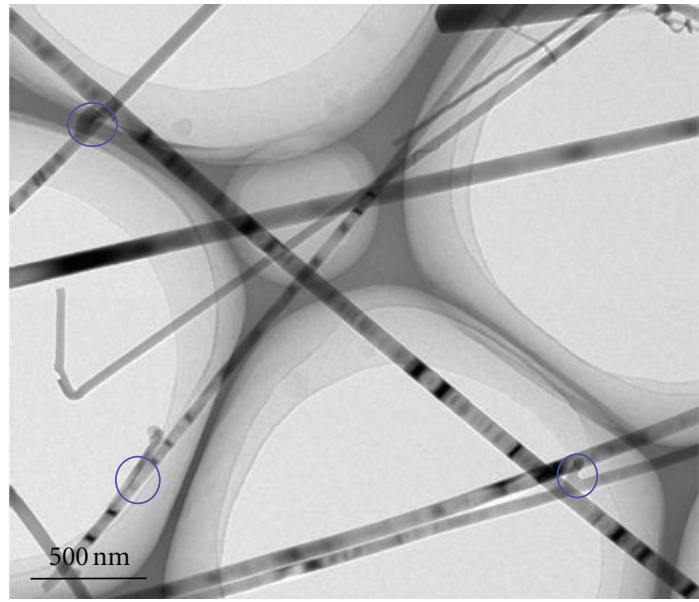

(b)

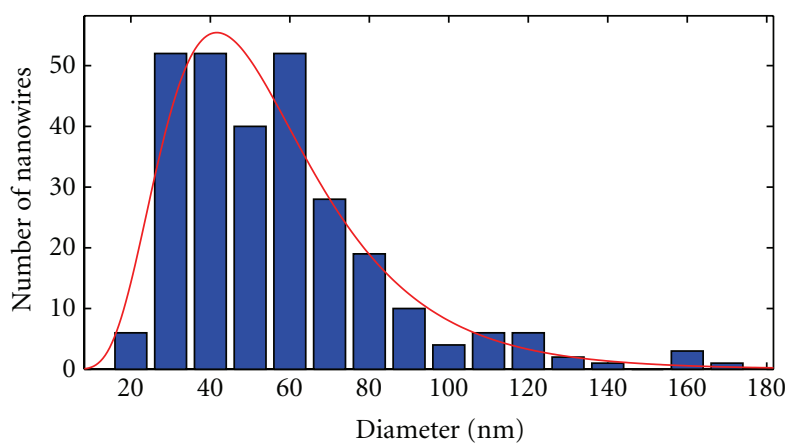

(c)

FIgURE 1: (a) SEM image of the as-grown $\mathrm{SiO}_{x} \mathrm{~N}_{y}$ nanowires. (b) TEM image of the as-grown $\mathrm{SiO}_{x} \mathrm{~N}_{y}$ nanowires. Circles mark the backboneto-branch junctions of Y-shaped nanowire formation. (c) histogram of the nanowire diameter distribution with the solid line representing a log-normal fit.

3.2. Growth Mechanism. Since the nanowires are synthesized without the aid of metal catalysis, vapor-solid (VS) growth mechanism is more plausible than the vapor-liquid-solid (VLS) growth model in this case. There was no other silicon species introduced into the system, so the silicon wafer was the only source of $\mathrm{Si}$ element. Sustained reaction of solid silicon or silicon dioxide $\left(\mathrm{SiO}_{2}\right)$ with $\mathrm{N}_{2}$ is not allowed since solid silicon and $\mathrm{SiO}_{2}$ are barriers for nitrogen diffusion [22]; therefore, gaseous $\mathrm{SiO}_{x}(x \approx 1)$ is the only source to directly supply Si element for Si-related nanowire growth [23]. In our experiment, hydrogen is introduced into the system as mixed gas, which can lead to the reaction of (1) and generate gaseous $\mathrm{SiO}_{x}$. Meanwhile, the residual oxygen in the furnace due to the low vacuum condition and leakage can also lead to the generation of gaseous $\mathrm{SiO}_{x}$ through the reaction (2):

$$
\begin{gathered}
\mathrm{SiO}_{2}(\mathrm{~s})+(2-x) \mathrm{H}_{2}(\mathrm{~g}) \longrightarrow \mathrm{SiO}_{x}(\mathrm{~g})+(2-x) \mathrm{H}_{2} \mathrm{O}(\mathrm{g}), \\
2 \mathrm{Si}(\mathrm{s})+x \mathrm{O}_{2} \longrightarrow 2 \mathrm{SiO}_{x}(\mathrm{~g}) .
\end{gathered}
$$

The reaction of $\mathrm{SiO}_{x}$ with introduced $\mathrm{N}_{2}$ lead to the formation of $\mathrm{SiO}_{x} \mathrm{~N}_{y}$, which is illustrated by (3):

$$
2 \mathrm{SiO}_{x}(\mathrm{~g})+y \mathrm{~N}_{2}(\mathrm{~g}) \longrightarrow 2 \mathrm{SiO}_{x} \mathrm{~N}_{y} .
$$

When we reduced the chamber temperature to $1100^{\circ} \mathrm{C}$, the growth of nanowire was not observed, while etched pits were found randomly distributed on the substrate shown in Figure 4(a), indicating that the temperature is critical to initiate the growth of nanowire. The EDS spectrum acquired from the pit showing only Si signal (Figure 4(b)) indicates that the silicon surface was etched, which also validate the reaction of (1) and (2). Thus, the formation process of the nanowires can be explained as follows: through the reactions (1) and (2), gaseous $\mathrm{SiO}_{x}$ was generated, and silicon oxide $\left(\mathrm{SiO}_{x}\right)$ nanoclusters were formed at the surface of the silicon substrates as illustrated in Figure $4(\mathrm{c})$. Then, $\mathrm{SiO}_{x}$ reacted with nitrogen to form $\mathrm{SiO}_{x} \mathrm{~N}_{y}$ nuclei according to the reaction indicated by (3) (Figure $4(\mathrm{~d})$ ). With continuous supply of $\mathrm{Si}, \mathrm{O}$, and $\mathrm{N}$ elements, the growth of $\mathrm{SiO}_{x} \mathrm{~N}_{y}$, nanowire was initiated and maintained Figure 4(e).

A similar experiment has been reported by Ran et al. [24], in which crystalline $\mathrm{Si}_{3} \mathrm{~N}_{4}$ /amorphous $\mathrm{SiO}_{2}$ nanocables were synthesized on silicon substrates under $\mathrm{N}_{2}$ atmosphere at $1250^{\circ} \mathrm{C}$ without using catalyst and $\mathrm{H}_{2}$. We believe that the difference is due to the different atmosphere and the temperature control curve. Another experiment reported by Farjas et al. [25] shows that oxygen partial pressure and the control 


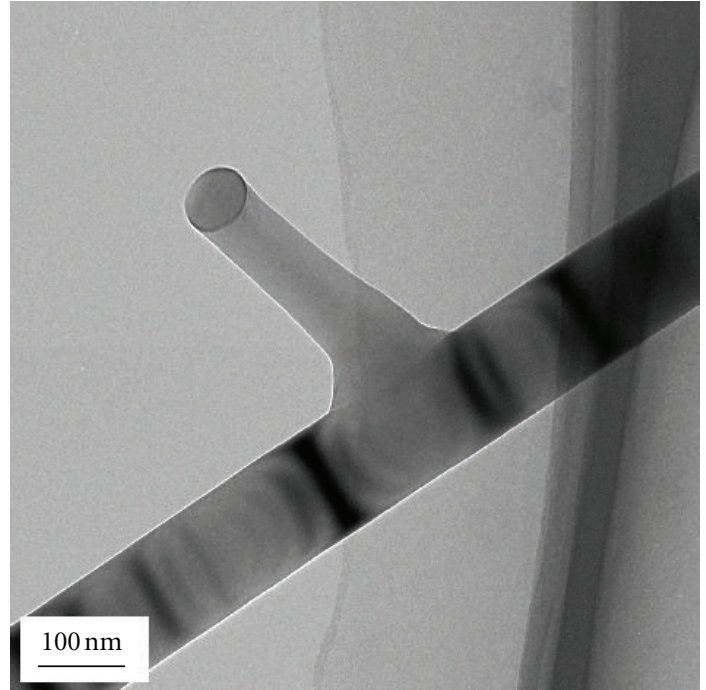

(a)

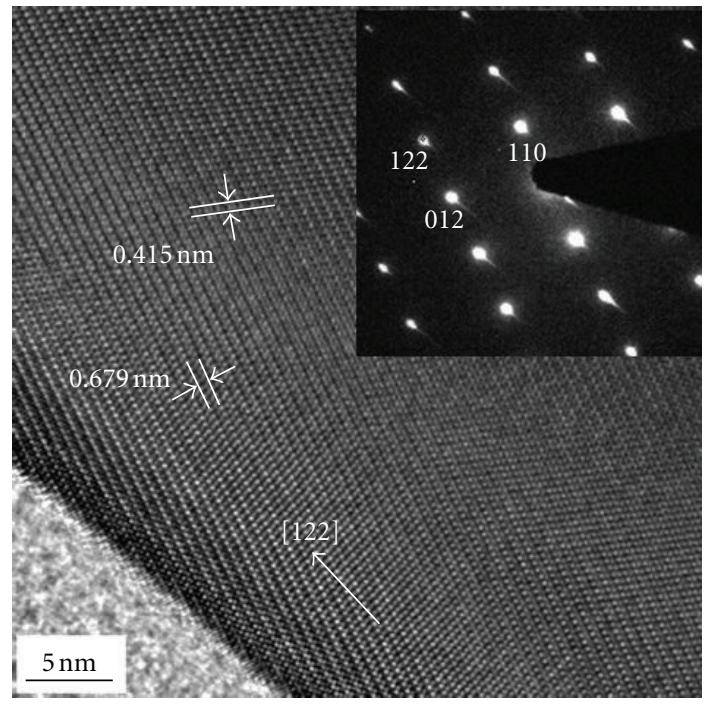

(c)

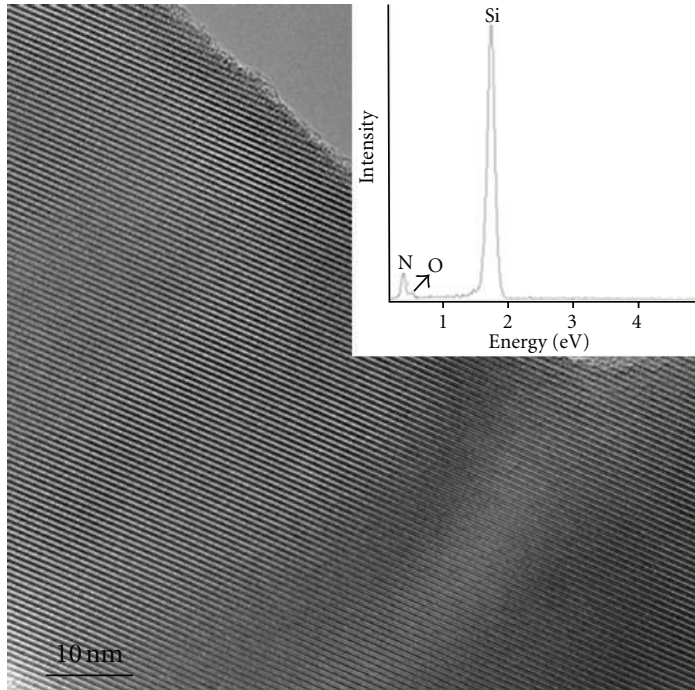

(b)

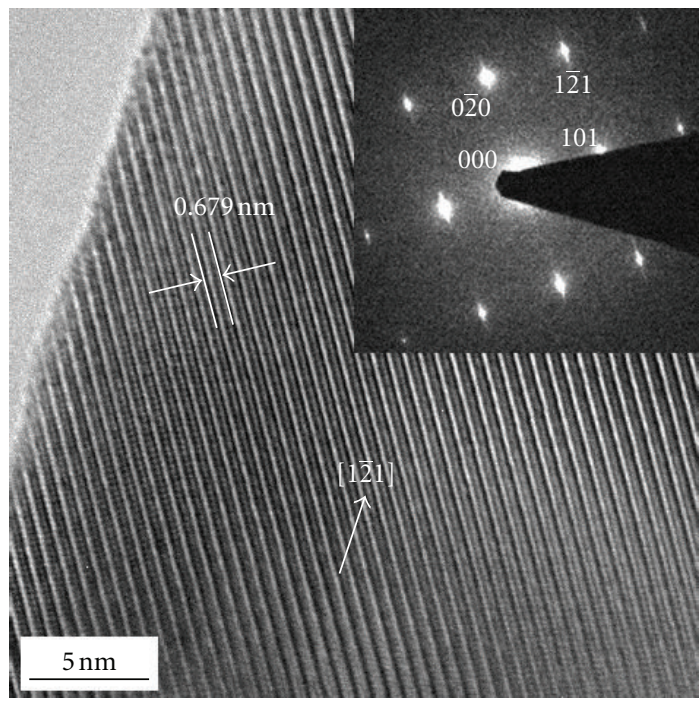

(d)

FIgURE 2: (a) and (b) are TEM image and HRTEM micrograph of Y-shaped $\mathrm{SiO}_{x} \mathrm{~N}_{y}$ nanowire obtained from one region marked in Figure 1(b), respectively, EDS spectrum as the inset in (b). (c) and (d) are typical HRTEM images of $\mathrm{SiO}_{x} \mathrm{~N}_{y}$ nanowires, each with the corresponding SAED pattern as an inset.

of temperature affect the formation of nanowires, in which $\mathrm{Si}_{3} \mathrm{~N}_{4}$ nanowires were obtained through a CVD mechanism.

\subsection{Optical Properties. To show the brightness and whiteness} of obtained nanowire mat, a thin carbon film has been patterned on Si wafer for comparison as shown in Figure 5(a), where black area is carbon film, and white rings are grown $\mathrm{SiO}_{x} \mathrm{~N}_{y}$ nanowires. Visual inspection of the samples shows no specular reflection and no obvious angular anisotropy. The optical properties of the nanowire mats were further characterized as shown in Figures 5(b) and 5(c).

The reflectivity was measured from 400 to $780 \mathrm{~nm}$ to quantitatively characterize the optical reflectance of $\mathrm{SiO}_{x} \mathrm{~N}_{y}$ nanowire mats. The reflectivity of two nanowire mats, defined as thicker mat of sample A and thinner mat of sample B, is compared and shown in Figure 5(b). At the whole wavelength range, the reflectivity of sample $\mathrm{A}$ is maintained above $70 \%$, and the highest point reaches out to $82 \%$, while sample B has a lower reflectivity with an obvious similar appearance. The high optical reflectivity and its slight variations in whole visible-light wavelength result in ultrabright whiteness of the nanowire mat. The results are comparable to the optical performance of the most brilliant white beetle scales reported by Vukusic et al., in which around $60 \%$ of incident visible-light is reflected [26].

Strongly diffusive reflectivity of the disordered nanowire mat arises mainly from multiple scattering [27], unlike ordered vertical nanowire mat which has low reflectivity, and its optical interactions can be calculated by solving Maxwell's 


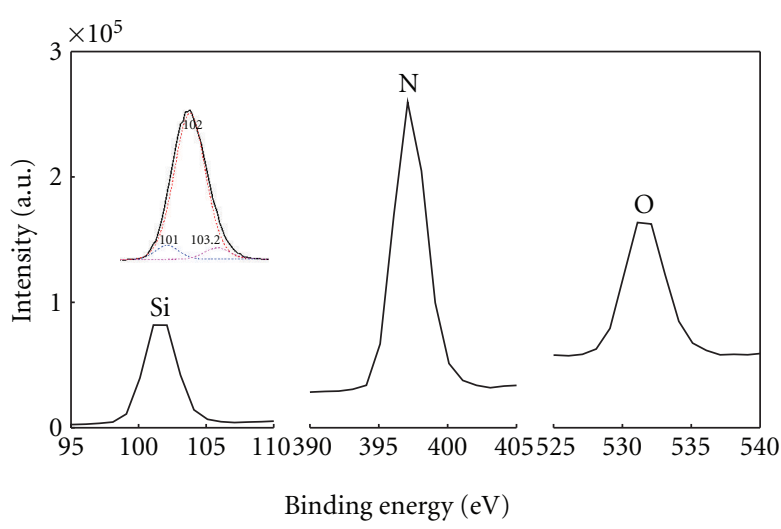

(a)

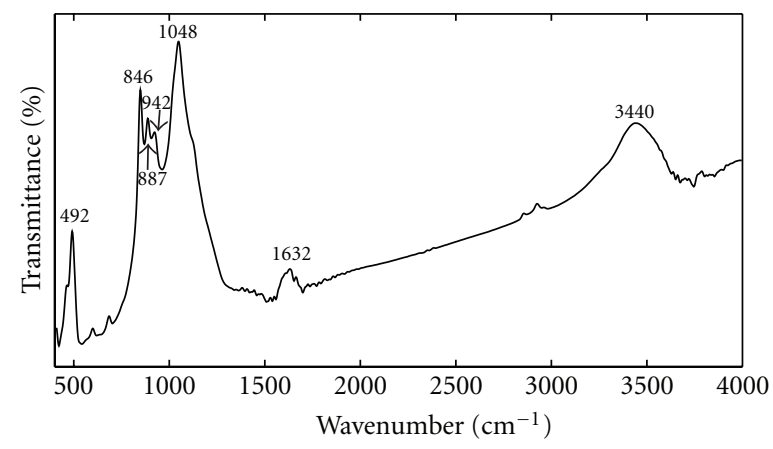

(b)

FIgURE 3: (a) XPS spectra of the $\mathrm{SiO}_{x} \mathrm{~N}_{y}$ nanowire around $\mathrm{Si} 2 \mathrm{p}, \mathrm{N}$ 1s and $\mathrm{O}$ 1s binding energies; the inset shows the fitting to the original Si 2p peak. (b) FT-IR spectra of the $\mathrm{SiO}_{x} \mathrm{~N}_{y}$ nanowire.

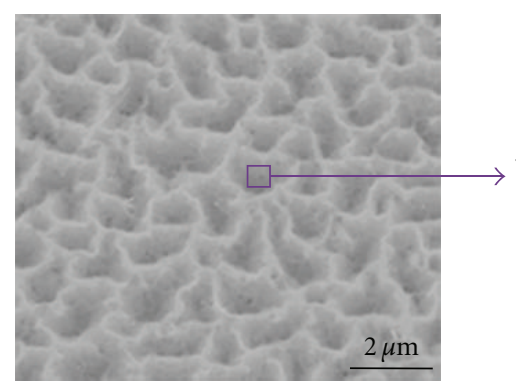

(a)

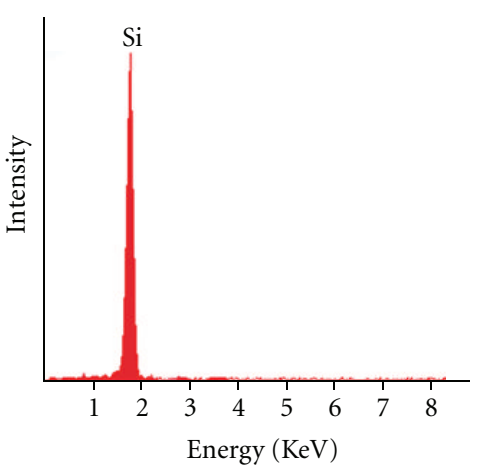

(b)

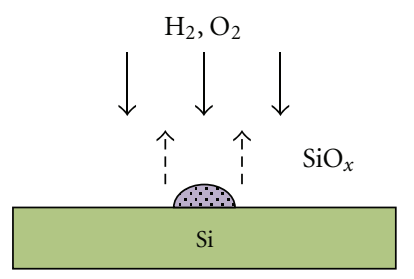

(c)

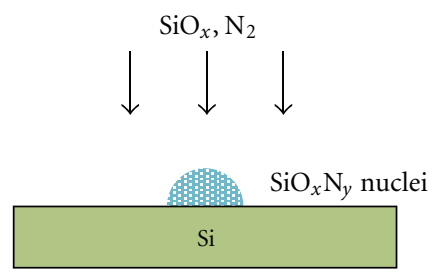

(d)

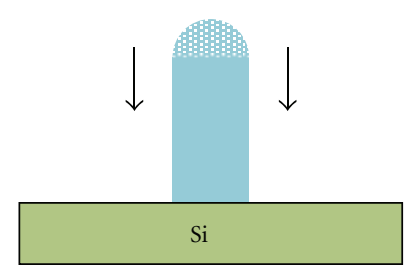

(e)

FIGURE 4: (a) SEM image of etched silicon wafer after the high-temperature handling at $1100^{\circ} \mathrm{C}$; (b) EDS spectrum acquired from the pit marked in (a); (c), (d), and (e) schematic growth process of the crystalline $\mathrm{SiO}_{x} \mathrm{~N}_{y}$ nanowires.

equations $[28,29]$. Disordered $\mathrm{SiO}_{x} \mathrm{~N}_{y}$ nanowire mats have an ultrabright appearance due to the interaction between scattering and absorption in the nanowires. The smallscatterer (Rayleigh) limit is valid for diameters $d<\lambda /(\pi n)$ with $n=3.5$, which sets the critical diameter well below $\lambda / 10$, where $\lambda$ is the optical wavelength. For nanowires with the thicker diameter than the critical diameter, light scattering strongly contributes to the nanowire optical reflectivity, which for a dense collection results in diffuse transport of light [15]. As characterized above, the diameter of the obtained nanowires follow a log-normalized distribution from $10-180 \mathrm{~nm}$, showing the existence of large amount of nanowires thicker than $\lambda / 10$ in the visible light range, which keeps the diffuse reflectivity at a high level. Moreover, for a sufficiently thick nanowire mat, photons experience a finite number of scattering events before being reemitted from the surface, corresponding to a total path length for the photon. This length [30] is much less than the mat thickness $(\sim 20 \mu \mathrm{m}$ in sample A), allowing the neglect of significant absorption by the silicon substrate, and therefore contribute to the high reflectivity. Meanwhile, the strong photonic nanowires with high refractive index may enhance their overall scattering efficiency $[15,26]$.

In sample B, the reflectivity is lower than that of sample A probably because of stronger substrate absorption. Thus, the enhancement of the optical reflectivity could be further 


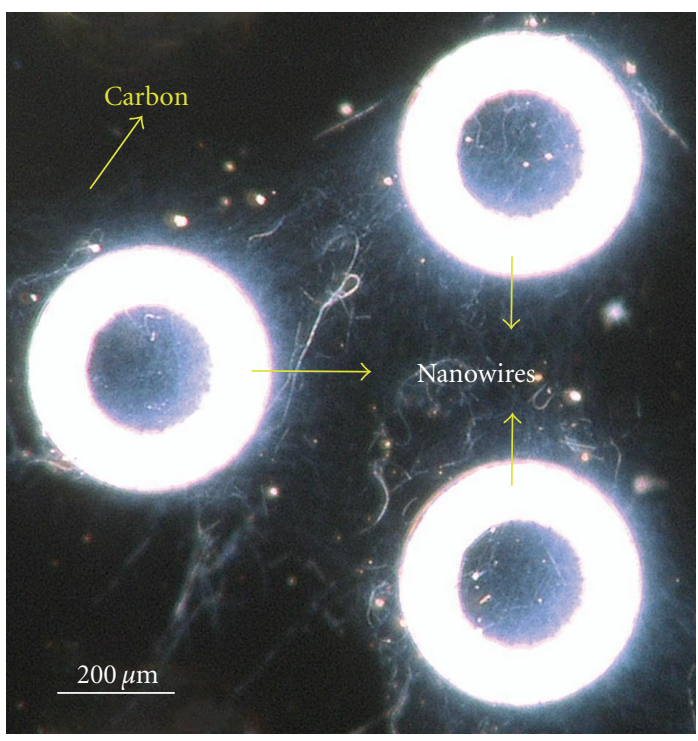

(a)

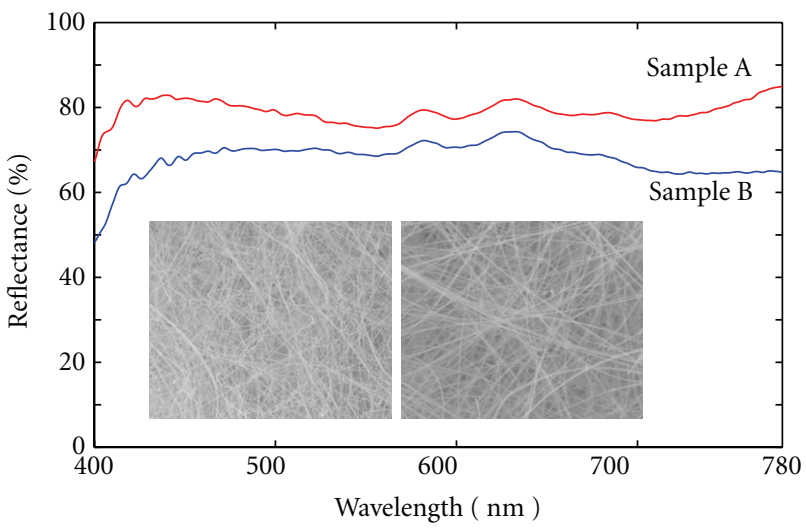

(b)

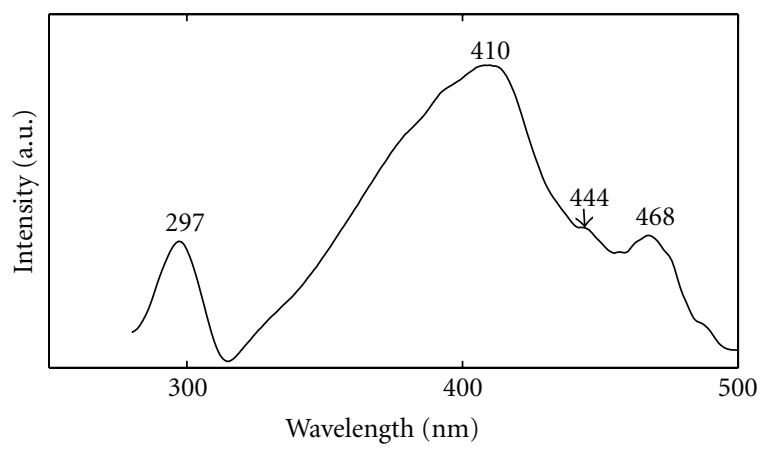

(c)

FIGURE 5: (a) photograph of $\mathrm{SiO}_{x} \mathrm{~N}_{y}$ nanowire mat on Si substrate with patterned carbon film. (b) reflectivity spectra from two samples of $\mathrm{SiO}_{x} \mathrm{~N}_{y}$ nanowire mats, and the inset shows SEM images of samples A and B from left to right. (c) room-temperature PL spectra of SiO $\mathrm{N}_{y}$ nanowires, using $258 \mathrm{~nm}$ line of a Xe lamp as the excitation.

expected through increasing the thickness of nanowire mat. The extraordinary optical diffusive reflection of these massproduced nanowires indicates their inherent potential in optoelectronic applications. It has been proved that a diffuse reflector cup can reduce deterministic whispering-gallery modes, and thus enhance light extraction [31]. Considering the extraordinary diffuse reflectivity, the $\mathrm{SiO}_{x} \mathrm{~N}_{y}$ nanowires could be also used as coating material of reflector cup, aimed at greatly improving the efficiency of LED lamps.

The PL property of single-crystalline $\mathrm{SiO}_{x} \mathrm{~N}_{y}$ nanowires was further studied. The PL spectrum, taken under excitation with the $258 \mathrm{~nm}$ line of a Xe lamp at room temperature, is presented in Figure 5(c). Two broad emissions are observed one of which is centered at $297 \mathrm{~nm}$, while the other one ranges from 380 to $500 \mathrm{~nm}$ with a maximum centered at $410 \mathrm{~nm}$ and two shoulders centered at 444 and $468 \mathrm{~nm}$, respectively. The strong peak around $410 \mathrm{~nm}$ arises from recombination either from the conduction band to the $\mathrm{N}_{2}{ }^{0}$ level or from the valence band to the $\mathrm{N}_{4}{ }^{+}$level [32]. The weak emission at $444 \mathrm{~nm}(\sim 2.8 \mathrm{eV})$, has been experimentally suggested by Noma et al. [33], originates from Si-N bonds in Si oxynitride. While the blue PL emission at $470 \mathrm{~nm}$ [34] and UVB PL emission at $297 \mathrm{~nm}$ [35] probably have an origin related to $\mathrm{Si}-\mathrm{O}$ bonds.

\section{Conclusion}

We have successfully synthesized large amount of N-rich single-crystalline $\mathrm{SiO}_{x} \mathrm{~N}_{y}$ nanowires through vapor-solid mechanism avoiding metal catalyst contamination. Their morphologies and optical properties were investigated. In this work, these nanowires were grown to form an ultrabright white disordered mat, displaying high diffuse reflectivity over the whole visible-light range which is largely determined by multiscattering of incident light. The extraordinary optical diffusive reflection of these mass-produced nanowires is comparable to that of the most brilliant white beetle scales found in nature. The application of these nanowires in white reflector could improve overall light extracting efficiency for highbright white lighting. Their ultrabright white appearance could also find applications in many other fields, such as cosmetics, paints, and tooth whitening. 


\section{Acknowledgments}

This work is financially supported by National Science Foundation of China number 90923019 and National Key Basic Research Special Fund of China number 2009CB724204.

\section{References}

[1] M. L. Green, E. P. Gusev, R. Degraeve, and E. L. Garfunkel, "Ultrathin $(<4 \mathrm{~nm}) \mathrm{SiO}_{2}$ and $\mathrm{Si}-\mathrm{O}-\mathrm{N}$ gate dielectric layers for silicon microelectronics: understanding the processing, structure, and physical and electrical limits," Journal of Applied Physics, vol. 90, pp. 2057-2121, 2001.

[2] J. Eng Jr., I. A. Hubner, J. Barriocanal, R. L. Opila, and D. J. Doren, "X-ray photoelectron spectroscopy of nitromethane adsorption products on $\mathrm{Si}(100)$ : a model for N 1 s core-level shifts in silicon oxynitride films," Journal of Applied Physics, vol. 95, no. 4, pp. 1963-1968, 2004.

[3] X. T. Zhang, Z. Liu, Z. Zheng, S. K. Hark, Y. B. Fu, and G. B. Zhang, "Synthesis and photoluminescence properties of wellaligned Ga-doped N-rich $\mathrm{SiO}_{x} \mathrm{~N}_{y}$ nanowire bundles," Applied Physics Letters, vol. 90, no. 18, Article ID 183110, 3 pages, 2007.

[4] R. Germann, H. W. M. Salemink, R. Beyeler et al., "Silicon oxynitride layers for optical waveguide applications," Journal of the Electrochemical Society, vol. 147, no. 6, pp. 2237-2241, 2000.

[5] K. Wörhoff, L. T. H. Hilderink, A. Driessen, and P. V. Lambeck, "Selicon oxynitride. A versatile material for integrated optic applications," Journal of the Electrochemical Society, vol. 149, no. 8, pp. F85-F91, 2002.

[6] D. M. Brown, P. V. Gray, F. K. Heumann, H. R. Philipp, and E. A. Taft, "Properties of $\mathrm{Si}_{x} \mathrm{O}_{y} \mathrm{~N}_{z}$ films on Si," Journal of The Electrochemical Society, vol. 115, pp. 311-317, 1968.

[7] X. Guo and T. P. Ma, "Tunneling leakage current in oxynitride: dependence on oxygen/nitrogen content," IEEE Electron Device Letters, vol. 19, no. 6, pp. 207-209, 1998.

[8] C. Xu, M. Kim, J. Chun et al., "Gallium-doped silicon nitride nanowires sheathed with amorphous silicon oxynitride," Scripta Materialia, vol. 53, no. 8, pp. 949-954, 2005.

[9] M. I. Alayo, I. Pereyra, W. L. Scopel, and M. C. A. Fantini, “On the nitrogen and oxygen incorporation in plasma-enhanced chemical vapor deposition (PECVD) $\mathrm{SiO}_{x} \mathrm{~N}_{y}$ films," Thin Solid Films, vol. 402, no. 1-2, pp. 154-161, 2002.

[10] T. Qiu, X. L. Wu, G. J. Wan, Y. F. Mei, G. G. Siu, and P. K. Chu, "Self-assembled growth and enhanced blue emission of $\mathrm{SiO}_{x} \mathrm{~N}_{y}$-capped silicon nanowire arrays," Applied Physics Letters, vol. 86, no. 19, Article ID 193111, pp. 1-3, 2005.

[11] Y. Xia, P. Yang, Y. Sun et al., "One-dimensional nanostructures: synthesis, characterization, and applications," Advanced Materials, vol. 15, no. 5, pp. 353-389, 2003.

[12] C. M. Lieber and Z. L. Wang, "Functional nanowires," MRS Bulletin, vol. 32, pp. 99-108, 2007.

[13] O. L. Muskens, S. L. Diedenhofen, B. C. Kaas et al., "large photonic strength of highly tunable resonant nanowire materials," Nano Letters, vol. 9, no. 3, pp. 930-934, 2009.

[14] J. G. Rivas, S. L. Diedenhofen, O. L. Muskens, and G. Grzela, "Tailoring light scattering of nanowires for photovoltaic applications," in Solar \& Alternative Energy, Proceedings of SPIE, 2010.

[15] O. L. Muskens, J. G. Rivas, R. E. Algra, E. P. A. M. Bakkers, and A. Lagendijk, "Design of light scattering in nanowire materials for photovoltaic applications," Nano Letters, vol. 8, no. 9, pp. 2638-2642, 2008.
[16] L. Gu, Y. Yu, V. Penmatsa, C. Wang, J. Maier, and P. A. Van Aken, "Synthesis and characterization of N-rich single crystalline $\mathrm{SiO}_{x} \mathrm{~N}_{y}$ nanowires with three-dimensional branches," Applied Physics Letters, vol. 94, no. 23, Article ID 231903, 2009.

[17] Z. H. Lu, S. P. Tay, R. Cao, and P. Pianetta, "The effect of rapid thermal $\mathrm{N}_{2} \mathrm{O}$ nitridation on the oxide/ $\mathrm{Si}(100)$ interface structure," Applied Physics Letters, vol. 67, pp. 2836-2838, 1995.

[18] E. C. Carr and R. A. Buhrman, "Role of interfacial nitrogen in improving thin silicon oxides grown in $\mathrm{N}_{2} \mathrm{O}$," Applied Physics Letters, vol. 63, no. 1, pp. 54-56, 1993.

[19] O. Benkherourou and J. P. Deville, "X-ray Photoelectron Spectroscopy of silicon oxynitride layers obtained by low-energy ion implantation," Applied Physics A Solids and Surfaces, vol. 46, no. 2, pp. 87-90, 1988.

[20] J. Zheng, X. Song, X. Li, and Y. Pu, "Large-scale production of amorphous silicon oxynitride nanowires by nickel-catalyzed transformation of silicon wafers in $\mathrm{NH}_{3}$ plasma," Journal of Physical Chemistry C, vol. 112, no. 1, pp. 27-34, 2008.

[21] L. Zheng, B. Huang, J. Wei, Y. Dai, and M. H. Whangbo, "Synthesis and optical properties of amorphous C-Si-O particles," Journal of Luminescence, vol. 131, no. 2, pp. 218224, 2011.

[22] H. M. Jennings, "On reactions between silicon and nitrogen," Journal of Materials Science, vol. 18, no. 4, pp. 951-967, 1983.

[23] G. Z. Yang, H. Cui, Y. Sun et al., "Simple catalyst-free method to the synthesis of $\beta$-SiC nanowires and their field emission properties," Journal of Physical Chemistry C, vol. 113, no. 36, pp. 15969-15973, 2009.

[24] G. Z. Ran, L. P. You, L. Dai et al., "Catalystless synthesis of crystalline $\mathrm{Si}_{3} \mathrm{~N}_{4} /$ amorphous $\mathrm{SiO}_{2}$ nanocables from silicon substrates and $\mathrm{N}_{2}$," Chemical Physics Letters, vol. 384, no. 13, pp. 94-97, 2004.

[25] J. Farjas, C. Rath, A. Pinyol, P. Roura, and E. Bertran, " $\mathrm{Si}_{3} \mathrm{~N}_{4}$ single-crystal nanowires grown from silicon microand nanoparticles near the threshold of passive oxidation," Applied Physics Letters, vol. 87, no. 19, Article ID 192114, pp. $1-3,2005$.

[26] P. Vukusic, B. Hallam, and J. Noyes, "Brilliant whiteness in ultrathin beetle scales,” Science, vol. 315, no. 5810, p. 348, 2007.

[27] R. A. Street, W. S. Wong, and C. Paulson, "Analytic model for diffuse reflectivity of silicon nanowire mats," Nano Letters, vol. 9, no. 10, pp. 3494-3497, 2009.

[28] J. Zhu, Z. Yu, G. F. Burkhart et al., "Optical absorption enhancement in amorphous silicon nanowire and nanocone arrays," Nano Letters, vol. 9, no. 1, pp. 279-282, 2009.

[29] L. Hu and G. Chen, "Analysis of optical absorption in silicon nanowire arrays for photovoltaic applications," Nano Letters, vol. 7, no. 11, pp. 3249-3252, 2007.

[30] R. A. Street, P. Qi, R. Lujan, and W. S. Wong, "Reflectivity of disordered silicon nanowires," Applied Physics Letters, vol. 93, pp. 163109-163111, 2008.

[31] H. Luo, J. K. Kim, Y. A. Xi et al., "Trapped whisperinggallery optical modes in white light-emitting diode lamps with remote phosphor," Applied Physics Letters, vol. 89, no. 4, Article ID 041125, 2006.

[32] W. Yang, L. Zhang, Z. Xie, J. Li, H. Miao, and L. An, "Growth and optical properties of ultra-long single-crystalline $\alpha-\mathrm{Si}_{3} \mathrm{~N}_{4}$ nanobelts," Applied Physics A, vol. 80, no. 7, pp. 1419-1423, 2005.

[33] T. Noma, K. S. Seol, H. Kato, M. Fujimaki, and Y. Ohki, "Origin of photoluminescence around 2.6-2.9 eV in silicon oxynitride," Applied Physics Letters, vol. 79, no. 13, pp. 19951997, 2001. 
[34] Z. Yang, Y. Zhang, D. Liu et al., "Selective synthesis of $\mathrm{SiO}_{2}$ NWs on Si substrate and their adjustable photoluminescence," Journal of Non-Crystalline Solids, vol. 356, no. 41-42, pp. 2207 2210, 2010.

[35] M. Cannas, "Luminescence properties of point defects in silica," GNSR 2001, State of Art and Future Development in Raman Spectroscopy and Related Techniques, 2002. 

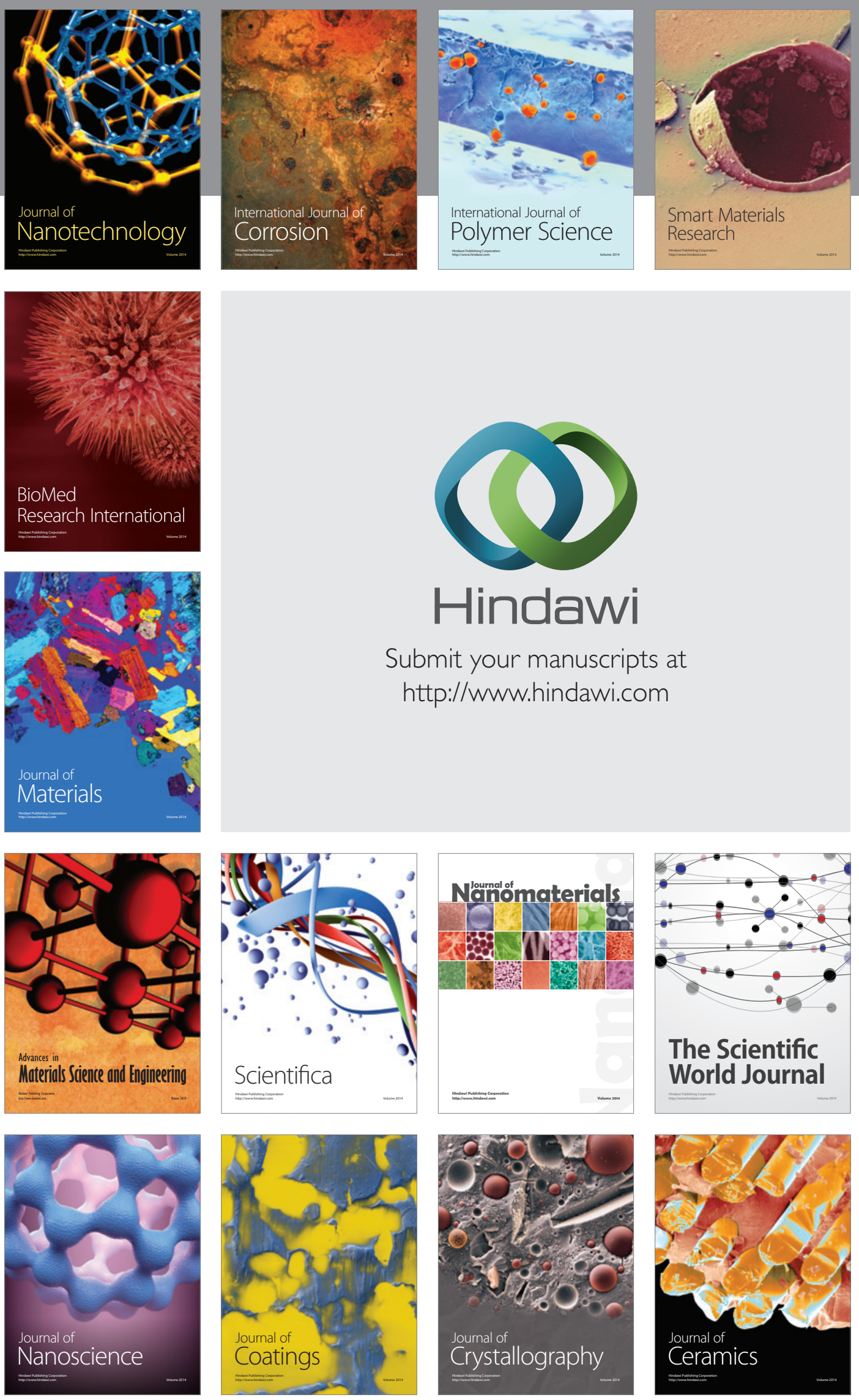

The Scientific World Journal

Submit your manuscripts at

http://www.hindawi.com

\section{World Journal}

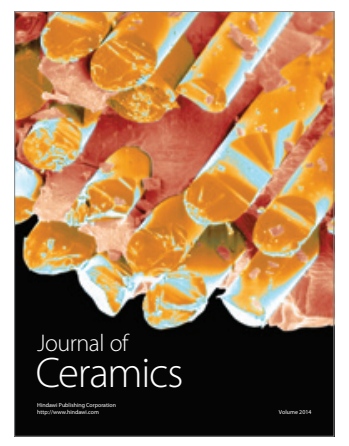

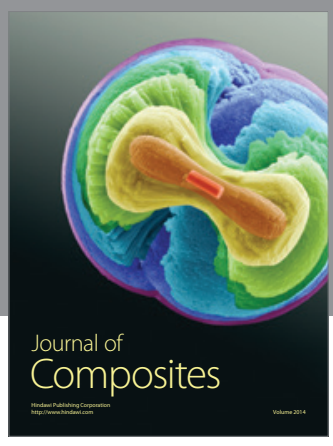
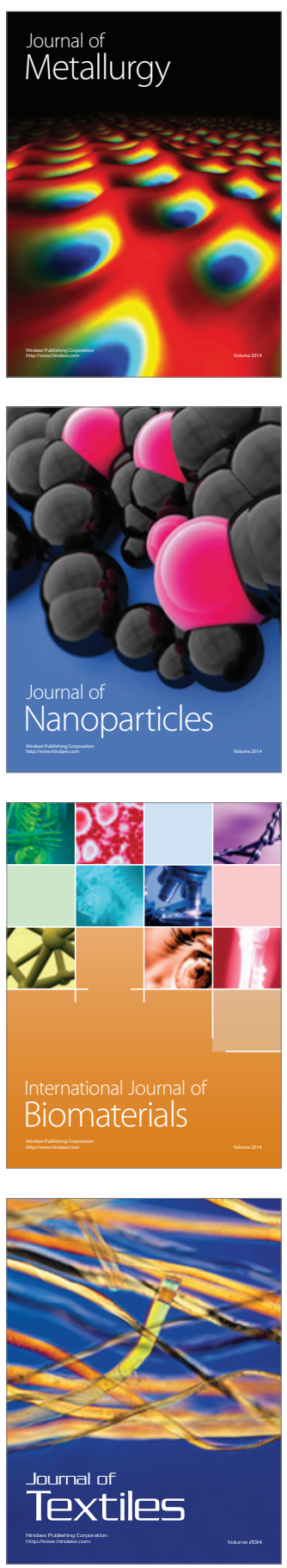